\title{
Diagnosis and Treatment of Hepatocellular Adenoma in the Netherlands: Similarities and Differences
}

\author{
S.M. van Aalten ${ }^{\mathrm{a}} \quad$ T. Terkivatan $^{\mathrm{a}} \quad$ R.A. de Man ${ }^{\mathrm{b}} \quad$ D.J. van der Windt ${ }^{\mathrm{a}} \quad$ N.F.M. Kok ${ }^{\mathrm{a}}$ \\ R. Dwarkasing ${ }^{c}$ J.N.M. IJzermans ${ }^{a}$ \\ Departments of a Surgery, ${ }^{b}$ Hepatogastroenterology and ${ }^{\mathrm{c}}$ Radiology, Erasmus Medical Centre, Rotterdam, \\ The Netherlands
}

\section{Key Words}

Hepatocellular adenoma $\cdot$ Hepatocellular adenoma, diagnosis $\cdot$ Oral contraceptives $\cdot$ Diagnosis and treatment questionnaire

\begin{abstract}
Background: The diagnosis of hepatocellular adenoma (HA) has a great impact on the lives of young women and may pose clinical dilemmas to the clinician since there are no standardized protocols to follow. We aimed to establish expert opinions on diagnosis and treatment of HA by collecting data from a nationwide questionnaire in the Netherlands. Methods: A questionnaire was sent to 20 Dutch hospitals known to offer hepatologic and surgical experience on liver tumours. Results: 17 hospitals (85\%) responded to the questionnaire. Annually, a median of 52 patients presented with a solid liver tumour. In 15 (88\%) hospitals, hepatic adenomas were diagnosed with contrast-enhanced, multiphase spiral CT or MRI. In 2 (12\%) hospitals, histology was required as part of a management protocol. Surveillance after withdrawal of oral contraceptives was the initial policy in all clinics. MRI, CT or ultrasound was used for follow-up. Criteria for surgical resection were a tumour size $>5 \mathrm{~cm}$ and abdominal complaints. In 5 (29\%) hospitals, patients were dismissed from follow-up after surgery. In complex cases (e.g. large,
\end{abstract}

multiple or centrally localized lesions, a wish for pregnancy), the treatment policy was highly variable. Pregnancy was not discouraged in 15 hospitals, but in 11 (65\%) of these, strictly defined conditions were noted: frequent follow-up, peripheral tumour localization that makes surgery easier if necessary, stable tumour size, and a good informed consent. Conclusion: The management of HAs in the Netherlands is rather uniform, except in complex cases in which multiple factors may influence policy.

Copyright $\odot 2010$ S. Karger AG, Basel

\section{Introduction}

The diagnosis of hepatocellular adenoma (HA) has a great impact on the lives of young women. HA is a benign tumour that usually presents as a solitary nodule; in a minority, multiple lesions are seen. This tumour is mostly detected in females within their reproductive years, associated with a long-term use of oral contraceptives (OC). The incidence is low, estimated to be $3-4 / 100,000$ in long-

Parts of this article have previously been published in Dutch [Ned Tijdschr Geneeskd 2007;16:151].

\section{KARGER}

Fax +4161306 1234

E-Mail karger@karger.ch

www.karger.com (c) 2010 S. Karger AG, Basel

$0253-4886 / 10 / 0271-0061 \$ 26.00 / 0$

Accessible online at:

www.karger.com/dsu
T. Terkivatan, $\mathrm{MD}, \mathrm{PhD}$

Department of Surgery, Erasmus Medical Centre Rotterdam

PO Box 2040, NL-3000 CA Rotterdam (The Netherlands)

Tel. +31 107040 704, Fax +31 104635058

E-Mail t.terkivatan@erasmusmc.nl 
term OC users [1]. During pregnancy the presence of HA can be complicated by growth and rupture which is induced by elevated hormone levels. Rupture and bleeding is associated with high maternal and fetal mortality [2-5]. Malignant transformation of HA to hepatocellular carcinoma (HCC) occurs rarely, but the true incidence of malignancy arising within HA is not known [6, 7]. Patients with HA may present with right upper quadrant abdominal pain secondary to bleeding, elevated liver enzymes and symptoms of life-threatening haemorrhage. However, most patients are asymptomatic. Since the introduction and widespread use of highly advanced imaging modalities, the number of solitary nodules that are found by accident has greatly increased in the last decennium [8].

The debate whether to manage solitary adenomas by surveillance or surgical resection continues. Conservative management of $\mathrm{HA}$ frequently implies cessation of the use of OC, intermittent follow-up by radiological imaging and negative advice regarding pregnancy. Surgical treatment of HA is associated with a risk of morbidity and mortality and does not guarantee relief of complaints. The most important reason for surgery is size of the lesion, since rupture as well as malignant transformation is seldom reported in lesions $<5 \mathrm{~cm}$ [7]. Patients with an adenoma which is $<5 \mathrm{~cm}$ and who do have a wish for pregnancy might also benefit from an early intervention in order to avoid an invasive treatment during pregnancy [9]. In practice, management strategy is not only determined by the size of the HA, but may also depend on complaints, the number and localization of nodules, a wish for pregnancy and surgical risks. Therefore, the policy for HA should be standardized while there is a place for a custom-made approach when considering these factors.

For this purpose, we collected data by a nationwide questionnaire in order to establish the most common approach in diagnosis and treatment of HA in the Netherlands.

\section{Methods}

In January 2005, a questionnaire was sent to 20 Dutch university centres and hospitals with a large programme of hepatobiliary surgery (table 1). Hepatobiliary surgeons in these hospitals all participate in the Dutch Liver Surgery Working Group of which is a division of the Dutch Society for Surgery. Both the departments of surgery and gastrointestinal diseases were invited to take part in this questionnaire. In May 2005, a reminder was sent to those who had not responded. The questionnaire included multiple-choice questions concerning incidence, diagnosis, treatment and follow-up of HA in the Netherlands. There was a possibility to add a comment next to each question. Specialists were asked
Table 1. Summary of questionnaire concerning policy in case of HA held in the Netherlands

\section{Incidence}

Are patients with solid liver tumours registered?

How many liver tumours are seen each year?

How many of them are benign?

Is there a multidisciplinary consultation team to determine treatment policy?

\section{Diagnosis}

Which imaging tools are being used for diagnosis?

Is there a role for liver biopsy in diagnosis of hepatocellular adenoma?

Are patients being tested for hepatitis B or C infection?

Therapy

Define surveillance

What are criteria to switch to invasive therapy?

What would be the first option?

Does the histological diagnosis of the resected specimen always confirm preoperative histological diagnosis?

Follow-up

Is there a follow-up after conservative management?

Is there a follow-up after surgery?

What kind of follow-up is being used and for how long?

What are the reasons for follow-up?

\section{Pregnancy}

What do you advise a patient with a wish for pregnancy?

Did you ever have a pregnant patient with an adenoma in situ?

what they would advise a women with a HA and a wish for pregnancy. In questions concerning treatment, we proposed that a conservative policy was followed initially. Thereafter, the question was asked on what criteria invasive treatment could have been chosen. Clinical dilemmas on HA were discussed on the basis of 5 imaginary cases. These cases had an open-answer option. Statistical data were analyzed using SPSS for Windows Version 13.0 (SPSS, Chicago, Ill., USA).

\section{Results}

Of the 20 hospitals ( 8 university centres and 9 general hospitals), 17 (85\%) responded. In 8 (47\%) of these 17 hospitals, data on incidence were from prospective databases. Data from the remaining hospitals were based on retrospective analyses or estimates by specialists.

\section{Incidence}

A median of 52 patients with a solid liver tumour presented annually per hospital (range 3-415). Between 1 van Aalten et al. 
and $40 \%$ of these patients had benign lesions with a differential diagnosis of adenoma, focal nodular hyperplasia, and haemangioma.

\section{Diagnostics}

In $16(94 \%)$ hospitals the policy for individual patients was determined by a multidisciplinary consultation of a surgeon, hepatologist, radiologist, oncologist and pathologist. The diagnosis of HA was usually based on imaging modalities. Multiphase spiral CT series were performed in $12(71 \%)$ hospitals. Multiphase contrast-enhanced MRI series were also applied in 12 hospitals. These data show that in 15 (88\%) hospitals HAs were diagnosed with contrast-enhanced, multiphase spiral CT or MRI series. In 2 (12\%) hospitals a liver biopsy was required for histological diagnosis. 13 (76\%) hospitals followed the standard policy to test patients with a solid nodule for hepatitis B and C. Additional tests included serum analyses for iron overload (8 (53\%) hospitals), $\alpha_{1}$-antitrypsin deficiency and alcohol consumption (both in 2 (12\%) hospitals).

\section{Treatment}

In 12 (71\%) hospitals the policy for HA was not structured in a protocol. Surveillance was the initial strategy in all hospitals. This policy consisted of withdrawal of OC and outpatient control by an imaging modality at least once. The kind of imaging tool that was used varied; MRI, CT or ultrasound was performed for follow-up in respectively 7 (41\%), 10 (59\%) and 8 (47\%) hospitals. The interval between follow-up episodes also varied. Followup after 6 months was mentioned in 10 (59\%) hospitals, but intervals of 3,4 , or 12 months were also reported. Another question concerned the situation in which a patient could resume the use of OC. This was assumed to be possible in 8 (47\%) hospitals. Six hospitals reported that in patients who did not show a regression of the lesion up to 1 year after stopping, the use of OC could be resumed. Comments were made that patients tended not to resume the use of OC and often wanted to have imaging information about renewed growth.

Major criteria for surgical resection were a tumour size $>5 \mathrm{~cm}$ (16 (94\%) hospitals) and abdominal complaints (15 clinics, 88\%). In those cases the decision for radical resection of the liver tumour was unanimous. In case of multiple adenomas the motivation for surgical intervention was determined by the pattern of complaints, size and localization of the lesions, opportunities to treat all tumours and the availability and use of alternative treatments such as radiofrequency ablation.
Other criteria were a wish for pregnancy, signs of malignancy, tumour growth, diagnostic doubt and localization in respectively 7 (41\%), 10 (59\%), 4 (24\%), 5 (29\%) and 7 (41\%) of all hospitals.

In $14(82 \%)$ hospitals it had occurred that histological analysis of the resected specimen showed another diagnosis compared to the preoperative diagnosis. Most of these cases were focal nodular hyperplasia. Five (29\%) hospitals mentioned a few cases in which a HCC was diagnosed after resection.

\section{Follow-Up}

Patients who were managed by surveillance were followed for a median period of 4 years (range 1-10) in all hospitals. In 14 (82\%) of the 17 hospitals, radiological tools were used to monitor growth and malignant transformation. After surgical resection, in 5 (29\%) hospitals follow-up was not considered necessary. In the other cases, patients were followed for a median period of 2 years (range 1-5). Growth or residual lesions were monitored. Pregnancy was not discouraged in 15 hospitals, but in 11 (65\%) of these, strictly defined conditions such as frequent follow-up (4 hospitals), a peripheral tumour localization that makes surgery easier if necessary ( 2 hospitals), a stable tumour size (2 hospitals), and a good informed consent about the risks in case of pregnancy ( 2 hospitals) were noted. No restrictions in patients with HA were imposed in 4 hospitals. In only 1 hospital, 1 patient was advised to postpone pregnancy until a surgical resection had been performed. Seven hospitals reported 1 or more patient(s) who presented with an adenoma during pregnancy; growth of the tumour occurred in 4 cases. Three of them fulfilled their pregnancy without complications. In 1 hospital, 1 patient underwent a surgical resection during the first trimester of pregnancy and another patient underwent a premature caesarean section in the third trimester because of a rapidly growing adenoma.

\section{Imaginary Cases}

Clinical dilemmas on HA were investigated on the basis of 5 imaginary cases (table 2). Small asymptomatic adenomas were managed by surveillance. In case of a large adenoma which was located centrally in the liver, the choice between surveillance and surgical resection was difficult to make and answers varied widely on this point. In 6 hospitals an additional biopsy was preferred in case of multiple adenomas in order to exclude malignancy. 
Table 2. Imaginary cases and answers of specialists from 17 hospitals with expertise in hepatobiliary surgery

\begin{tabular}{|c|c|c|}
\hline Case & Policy & Hospitals, $\mathrm{n}$ \\
\hline \multirow{4}{*}{$\begin{array}{l}\text { 48-year-old female with a hilar-located adenoma of } 8 \mathrm{~cm} \\
\text { and signs of intrahepatic bleeding }\end{array}$} & Resection if possible & $7(41 \%)$ \\
\hline & Arterial embolisation & $4(24 \%)$ \\
\hline & RFA & $1(6 \%)$ \\
\hline & Observation & $5(29 \%)$ \\
\hline \multirow{2}{*}{$\begin{array}{l}\text { 23-year-old female with an incidentally found adenoma } \\
\text { located in the middle of the right lobe; she uses OC and } \\
\text { has a clear wish for pregnancy in future }\end{array}$} & Surveillance & $11(65 \%)$ \\
\hline & RFA & $2(12 \%)$ \\
\hline 40-year-old obese female diagnosed with & Surveillance & $7(41 \%)$ \\
\hline 4 lesions suspected for adenoma: 2 are & Resection of largest one & $4(24 \%)$ \\
\hline \multirow{2}{*}{$\begin{array}{l}\text { located in the right liver (diameter } 6 \text { and } 2 \mathrm{~cm} \text { ) } \\
\text { and } 2 \text { in the left (diameter } 2 \text { and } 3 \mathrm{~cm} \text { ) }\end{array}$} & Resection of largest adenoma and RFA of other lesions & $5(29 \%)$ \\
\hline & RFA of largest lesion & $1(6 \%)$ \\
\hline \multirow{3}{*}{$\begin{array}{l}\text { Female patient with an adenoma of } 4 \mathrm{~cm} \text {, which did not } \\
\text { show regression after stopping OC; she wants to become } \\
\text { pregnant }\end{array}$} & Frequent surveillance during pregnancy & $8(47 \%)$ \\
\hline & Resection or RFA before pregnancy & $7(41 \%)$ \\
\hline & $\begin{array}{l}\text { Informed consent, the patient has to decide for surveillance, } \\
\text { surgery or RFA }\end{array}$ & $2(12 \%)$ \\
\hline
\end{tabular}

RFA = Radiofrequency ablation; OC = oral contraceptives.

\section{Discussion}

Data obtained from this survey show that most Dutch specialists who responded to the questionnaire rely on multiphase contrast-enhanced CT or MRI series to confirm the diagnosis of HA. Using these techniques it is usually possible to differentiate adenomas from other benign lesions such as focal nodular hyperplasia and haemangioma as well as from malignancies [10-12]. No strict consensus for the optimal imaging work-up of liver lesions was found. Most often, MRI was applied to characterize liver lesions by using multiphase dynamic contrastenhanced techniques. The availability of tissue-specific contrast media in MRI, e.g. gadobenate dimeglumine, which is one of the most recently used agents in hepatic imaging, permits lesion characterisation based on its cellular composition, enhancement pattern and morphological features [13]. The use of this highly advanced imaging modality during differential diagnosis of a focal liver lesion will prevent unnecessary liver biopsy or surgery. The role of ultrasound-guided percutaneous liver biopsy is debatable as various studies indicate that histology on needle biopsies may not be conclusive regarding $\mathrm{HA}$, fo- cal nodular hyperplasia and well-differentiated HCC [1416]. Only 2 hospitals in our questionnaire indicated that a biopsy was required to establish the diagnosis of HA.

Conservative management, including imaging surveillance and discontinuation of $\mathrm{OC}$, was the initial policy in all hospitals (fig. 1). This strategy is in accordance with several studies advocating a conservative approach $[14,15,17,18]$. Some authors emphasize the possibility of malignant transformation in large lesions $[17,19,20]$ and tend to resect HAs $>5 \mathrm{~cm}$. The relationship between tumour size and bleeding risk is unclear. After rupture or bleeding of HAs it is difficult to identify the size of the original tumour as a haematoma may disturb imaging reliability. While most patients with an adenoma are asymptomatic, up to $60 \%$ of those who present with symptoms do have signs of bleeding $[15,19,21]$. Although tumour size is the most important factor to decide whether to manage by observation or to perform a surgical resection, abdominal pain was an equally important determinant. Surgical resection of HA is described as an effective method to reduce complaints. However, various experts stress that it should be ascertained that symptoms are related to the HA [15]. Abdominal pain 

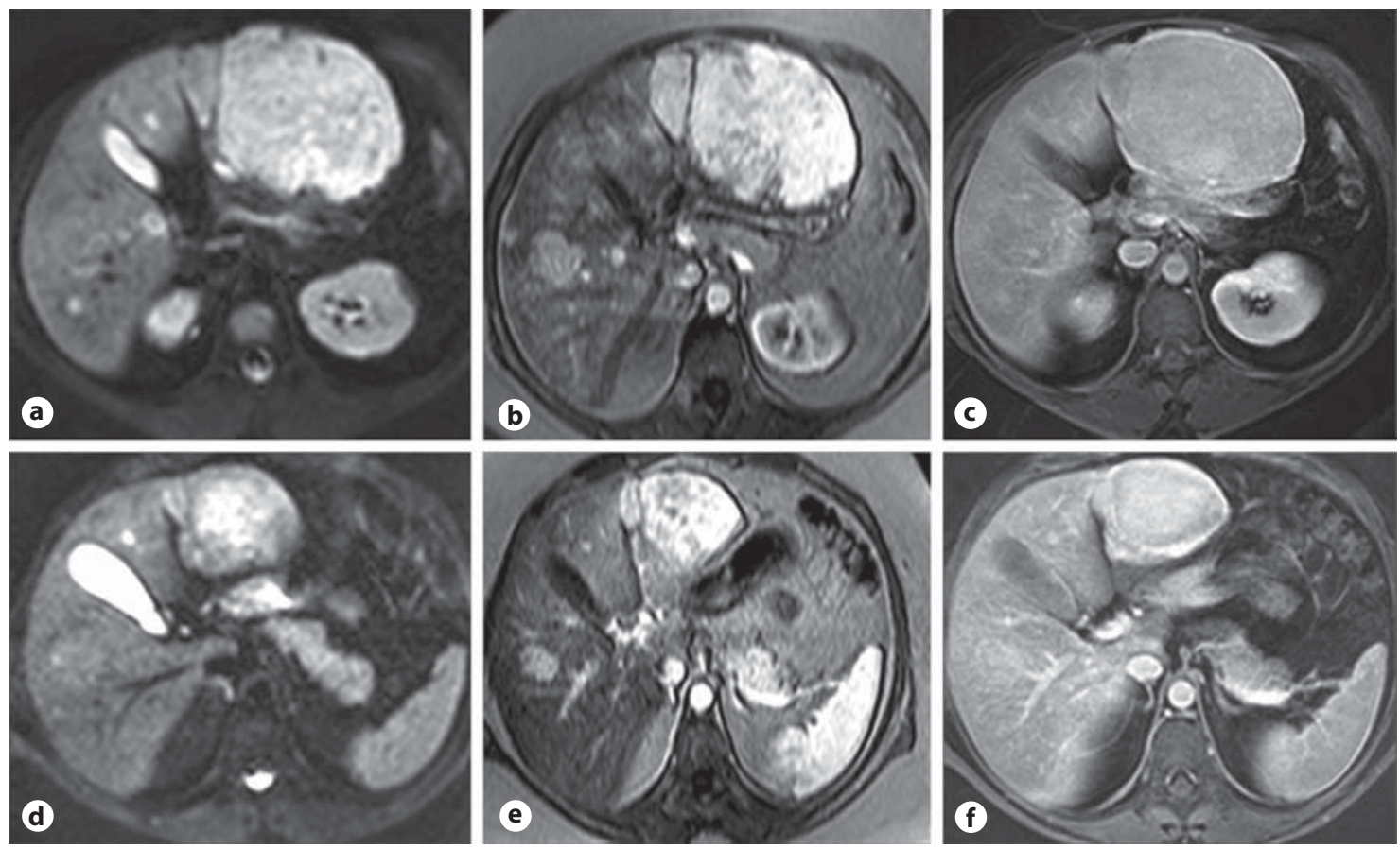

Fig. 1. Contrast-enhanced multiphase MRI series of a patient with $H A: \mathbf{a} \mathrm{T}_{2}$-weighted, $\mathbf{b}$ arterial phase, $\mathbf{c}$ delayed phase during use of OC, $\mathbf{d} \mathrm{T}_{2}$-weighted, e arterial phase, and $\mathbf{f}$ delayed phase after stopping use of oral contraceptives.

often arises due to the sudden increase in volume of a haematoma. Bleeding can be managed conservatively and resorption of a haematoma can equally reduce symptoms. Many experts answered to favour a wait-and-see policy in dynamically stable patients [22]. The localization of a HA and the surgical risks determine whether a surgical approach is feasible. If there are doubts about radiological diagnosis, specialists are more likely to favour surgical resection, i.e. to exclude HCC.

Clinical dilemmas occur when multiple factors mentioned above are to be considered. In these situations it is complex to define an appropriate treatment strategy and comments varied considerably between specialists. The use of imaging modalities is essential during follow-up of $\mathrm{HA}$, since there is a large discrepancy between clinical signs of patients and the size or growth of the adenoma.

It has to be noted that it is a difficult decision to discourage pregnancy in otherwise healthy young women. Pregnancy was not discouraged in most of the clinics, but in most of the imaginary cases, a majority of experts wanted to exclude the risk of bleeding by resection before pregnancy. In a recently published review of 27 women who were pregnant with a HA in situ, rupture occurred in 16 of them, leading to death of mother or child in 7 cases [5]. However, it has to be noted that all of these case reports were published in the 1970s or 1980s. In this period, the routine use of ultrasonography was less frequent and there might have been a delay in diagnosis because of confusion with other pregnancy-related diseases like preeclampsia or pulmonary embolism. When women are informed about the potential risks, it is safe to allow pregnancy, especially if the lesion is accessible for limited surgical resection. It seems unjustified to discourage all women with HAs from pregnancy.

In women with a clear diagnosis of a single HA with a diameter $<5 \mathrm{~cm}$ and without complaints, most experts advise a conservative policy. After discontinuation of OC, HA does not seem to grow and the likelihood of bleeding decreases [23]. If the diagnosis of $\mathrm{HA}$ is uncertain and the diagnosis HCC remains in differential diagnosis, radical resection of the tumour is recommended. At our centre, surgical treatment of solitary adenomas is restricted to patients having lesions that measure $\geq 5 \mathrm{~cm}$, in those patients in which malignancy cannot be excluded and to lesions that do not show adequate regression after discontinuation of OC, especially in case of women 
with a wish for pregnancy $[9,15]$. However, due to the invasive nature of hepatic surgery and the risk of postoperative morbidity, other treatment strategies are needed. Several authors have described the successful application of minimal invasive strategies such as transarterial (chemo)embolisation and radiofrequency ablation [2428]. The role of these alternative treatments in case of HA still needs to be established in clinical studies.

Recent identification of gene mutations, such as mutations in hepatocyte nuclear factor $1 \alpha$ and $\beta$-catenin that seem to be correlated to the phenotype of $\mathrm{HA}$, will create a basis for a new genotype/phenotype classification of HAs. These developments will hopefully permit significant improvements in liver biopsy interpretation, creating the possibility to predict the risk of bleeding and malignant transformation and the ability to propose better guidelines in terms of surveillance and treatment $[29,30]$.

We conclude that the management of HAs in the Netherlands is rather uniform. However, in complex situations where multiple factors may play a role in determining the management strategy, such as pregnancy or multiple adenomas, respondents' opinions are very variable regarding treatment and follow-up.
Because evidence-based data are scarce in the literature, it is recommended that Dutch specialists exchange knowledge and data of patients with HA to develop the most adequate guidelines in complex situations, justifying a custom-made approach. This will prevent unnecessary surgery and may offer well-balanced advice on pregnancy in case of more complex cases.

\section{Acknowledgements}

We thank the following hospitals for responding to the questionnaire: VU Medical Centre, Amsterdam; University Medical Centre, Groningen; Academic Hospital, Maastricht; Academic Medical Centre, Amsterdam; University Medical Centre St. Radboud, Nijmegen; University Medical Centre, Leiden; University Medical Centre, Utrecht; Erasmus Medical Centre, Rotterdam; Maasland Hospital, Sittard; Reinier de Graaf Groep, Delft; Medical Centre, Leeuwarden; Gelre Hospital, Apeldoorn; Maxima Medical Centre, Veldhoven; Medical Spectrum Twente, Enschede; Rijnstate Hospital, Arnhem; Amphia Hospital, Breda; Haaglanden Medical Centre, the Hague.

\section{References}

1 Reddy KR, Schiff ER: Approach to a liver mass. Semin Liver Dis 1993;13:423-435.

-2 Kent DR, Nissen ED, Nissen SE, Ziehm DJ: Effect of pregnancy on liver tumor associated with oral contraceptives. Obstet Gynecol 1978;51:148-151.

-3 Hayes D, Lamki H, Hunter IW: Hepatic-cell adenoma presenting with intraperitoneal haemorrhage in the puerperium. Br Med J 1977;2:1394.

4 Monks PL, Fryar BG, Biggs WW: Spontaneous rupture of an hepatic adenoma in pregnancy with survival of mother and fetus. Aust NZ J Obstet Gynaecol 1986;26:155-157.

5 Cobey FC, Salem RR: A review of liver masses in pregnancy and a proposed algorithm for their diagnosis and management. Am J Surg 2004;187:181-191.

6 Grazioli L, Federle MP, Brancatelli G, Ichikawa T, Olivetti L, Blachar A: Hepatic adenomas: imaging and pathologic findings. Radiographics 2001;21:877-892.

7 Deneve JL, Pawlik TM, Cunningham S, Clary B, Reddy S, Scoggins CR, Martin RC, D’Angelica M, Staley CA, Choti MA, Jarnagin WR, Schulick RD, Kooby DA: Liver cell adenoma: a multicenter analysis of risk factors for rupture and malignancy. Ann Surg Oncol 2009;16:640-648.
8 De Rave S, Hussain SM: A liver tumour as an incidental finding: differential diagnosis and treatment. Scand J Gastroenterol Suppl 2002;236:81-86.

$\checkmark 9$ Terkivatan T, de Wilt JHW, de Man RA, IJzermans JNM: Management of hepatocellular adenoma during pregnancy. Liver 2000;20:186-187.

10 Hussain SM, Semelka RC: Hepatic imaging: comparison of modalities. Radiol Clin North Am 2005;43:929-947.

11 Ichikawa T, Federle MP, Grazioli L, Nalesnik M: Hepatocellular adenoma: multiphasic CT and histopathologic findings in 25 patients. Radiology 2000;214:861-868.

-12 Ruppert-Kohlmayr AJ, Uggowitzer MM, Kugler C, Zebedin D, Schaffler G, Ruppert GS: Focal nodular hyperplasia and hepatocellular adenoma of the liver: differentiation with multiphasic helical CT. AJR Am J Roentgenol 2001;176:1493-1498.

$\checkmark 13$ Lee HY, Lee JM, Kim SH, Shin KS, Lee JY, Han JK, Choi BI: Detection and characterization of focal hepatic lesions: comparative study of MDCT and gadobenate dimeglumine-enhanced MR imaging. Clin Imaging 2008;32:287-295.
14 Charny CK, Jarnagin WR, Schwartz LH, Frommeyer HS, DeMatteo RP, Fong Y, Blumgart LH: Management of 155 patients with benign liver tumours. Br J Surg 2001;88: 808-813.

15 Terkivatan T, de Wilt JHW, de Man RA, van Rijn RR, Zondervan PE, Tilanus HW, IJzermans JNM: Indications and long-term outcome of treatment for benign hepatic tumours: a critical appraisal. Arch Surg 2001; 136:1033-1038

16 Descottes B, Glineur D, Lachachi F, Valleix D, Paineau J, Hamy A, Morino M, Bismuth H, Castaing D, Savier E, Honore P, Detry O, Legrand M, Azagra JS, Goergen M, Ceuterick M, Marescaux J, Mutter D, de Hemptinne B, Troisi R, Weerts J, Dallemagne B, Jehaes C, Gelin M, Donckier V, Aerts R, Topal B, Bertrand C, Mansvelt B, Van Krunckelsven L, Herman D, Kint M, Totet E, Schockmel R, Gigot JF: Laparoscopic liver resection of benign liver tumours. Surg Endosc 2003; 17:23-30.

17 Ault GT, Wren SM, Ralls PW, Reynolds TB, Stain SC: Selective management of hepatic adenomas. Am Surg 1996;62:825-829.

18 Choi BY, Nguyen MH: The diagnosis and management of benign hepatic tumours. J Clin Gastroenterol 2005;39:401-412. 
19 Leese T, Farges O, Bismuth H: Liver cell adenomas. A 12-year surgical experience from a specialist hepato-biliary unit. Ann Surg 1988;208:558-564.

20 Chiche L, Dao T, Salame E, Galais MP, Bouvard N, Schmutz G, Rousselot P, BioulacSage P, Segol P, Gignoux M: Liver adenomatosis: reappraisal, diagnosis, and surgical management: eight new cases and review of the literature. Ann Surg 2000;231:74-81.

21 Barthelmes L, Tait IS: Liver cell adenoma and liver cell adenomatosis. HPB (Oxford) 2005; 7:186-196.

-22 Terkivatan T, de Wilt JHW, de Man RA, van Rijn RR, Tilanus HW, IJzermans JNM: Treatment of ruptured hepatocellular adenoma. Br J Surg 2001;88:207-209.
23 Van der Windt DJ, Kok NF, Hussain SM, Zondervan PE, Alwayn IP, de Man RA, IJzermans JNM: Case-orientated approach to the management of hepatocellular adenoma. Br J Surg 2006;93:1495-1502.

24 Kim YI, Chung JW, Park JH: Feasibility of transcatheter arterial chemoembolization for hepatic adenoma. J Vasc Interv Radiol 2007; 18:862-867.

25 Atwell TD, Brandhagen DJ, Charboneau JW, Nagorney DM, Callstrom MR, Farrell MA: Successful treatment of hepatocellular adenoma with percutaneous radiofrequency ablation. AJR Am J Roentgenol 2005; 184:828831.

26 Buscarini L, Rossi S, Fornari F, Di Stasi M, Buscarini E: Laparoscopic ablation of liver adenoma by radiofrequency electrocautery. Gastrointest Endosc 1995;41:68-70.

-27 Fujita S, Kushihata F, Herrmann GE, Mergo PJ, Liu C, Nelson D, Fujikawa T, Hemming AW: Combined hepatic resection and radiofrequency ablation for multiple hepatic adenomas. J Gastroenterol Hepatol 2006;21: 1351-1354.
8 Rhim H, Lim HK, Kim YS, Choi D: Percutaneous radiofrequency ablation of hepatocellular adenoma: initial experience in $10 \mathrm{pa}$ tients. J Gastroenterol Hepatol 2008;23: 422-427.

29 Bioulac-Sage P, Blanc JF, Rebouissou S, Balabaud C, Zucman-Rossi J: Genotype phenotype classification of hepatocellular adenoma. World J Gastroenterol 2007;13:26492654.

30 Zucman-Rossi J, Jeannot E, Tran van Nhieu J, Scoazec J, Guettier C, Rebouissou S, Bacq Y, Leleurtre E, Paradis V, Michalak S, Wendum D, Chiche M, Mellottee L, Laurent C, Partensky C, Zafrani ES, Laurent-Puig P, Balabaud C, Bioulax-Sage P: Genotype-phenotype in hepatocellular adenoma: New classification and relationship with HCC. Hepatology 2006;43:515-524. 